\title{
Centers for Disease Control and Prevention Guideline on the Diagnosis and Management of Mild Traumatic Brain Injury Among Children
}

Angela Lumba-Brown, MD, Keith Owen Yeates, PhD, Kelly Sarmiento, MPH, Matthew J. Breiding, PhD, Tamara M. Haegerich, PhD, Gerard A. Gioia, PhD, Michael Turner, MD, Edward C. Benzel, MD, Stacy J. Suskauer, MD, Christopher C. Giza, MD, Madeline Joseph, MD, Catherine Broomand, PhD, Barbara Weissman, MD, Wayne Gordon, PhD, David W. Wright, MD, Rosemarie Scolaro Moser, PhD, Karen McAvoy, PhD, Linda Ewing-Cobbs, PhD, Ann-Christine Duhaime, MD, Margot Putukian, MD, Barbara Holshouser, PhD, David Paulk, EdD, Shari L. Wade, PhD, Stanley A. Herring, MD, Mark Halstead, MD, Heather T. Keenan, MD, PhD, Meeryo Choe, MD, Cindy W. Christian, MD, Kevin Guskiewicz, PhD, ATC, P. B. Raksin, MD, Andrew Gregory, MD, Anne Mucha, PT, DPT, H. Gerry Taylor, PhD, James M. Callahan, MD, John DeWitt, PT, DPT, ATC, Michael W. Collins, PhD, Michael W. Kirkwood, PhD, John Ragheb, MD, Richard G. Ellenbogen, MD, Theodore J. Spinks, MD, Theodore G. Ganiats, MD, Linda J. Sabelhaus, MLS, Katrina Altenhofen, MPH, Rosanne Hoffman, MPH, Tom Getchius, BA, Gary Gronseth, MD, Zoe Donnell, MA, Robert E. O’Connor, MD, MPH, Shelly D. Timmons, MD, PhD Stanford University School of Medicine, Stanford, California (Lumba-Brown); University of Calgary, Calgary, Alberta, Canada (Yeates); Division of Unintentional Injury Prevention, National Center for Injury Prevention and Control, Centers for Disease Control and Prevention (CDC), Atlanta, Georgia (Sarmiento, Breiding, Haegerich); Children's National Health System, George Washington University School of Medicine, Washington, DC (Gioia); Goodman Campbell Brain and Spine, Indianapolis, Indiana (Turner); Cleveland Clinic, Cleveland, Ohio (Benzel); Kennedy Krieger Institute, Johns Hopkins University School of Medicine, Baltimore, Maryland (Suskauer); The University of California, Los Angeles (UCLA) Steve Tisch BrainSPORT Program, UCLA Mattel Children's Hospital, David Geffen School of Medicine at UCLA, Los Angeles (Giza, Choe);

Corresponding Author: Matthew J. Breiding, PhD, Division of Unintentional Injury Prevention, National Center for Injury Prevention and Control, Centers for Disease Control and Prevention, 4770 Buford Hwy NE, Mail Stop F62, Atlanta, GA 30341 (dvi8@cdc.gov).

Author Contributions: Dr Breiding had full access to all of the data in the study and takes responsibility for the integrity of the data and the accuracy of the data analysis.

Concept and design: Lumba-Brown, Yeates, Sarmiento, Breiding, Getchius, Gronseth, Joseph, Timmons.

Acquisition, analysis, or interpretation of data: Lumba-Brown, Yeates, Haegerich, Gioia, Turner, Benzel, Suskauer, Giza, Joseph,

Broomand, Weissman, Gordon, Wright, Moser, McAvoy, Ewing-Cobbs, Duhaime, Holshouser, Paulk, Wade, Herring, Halstead,

Keenan, Choe, Christian, Raksin, Gregory, Mucha, Taylor, Callahan, DeWitt, Guskiewicz, Kirkwood, Ragheb, Ellenbogen, Spinks,

Ganiats, Sabelhaus, Altenhofen, Hoffman, Gronseth, Donnell, O’Connor, Timmons.

Drafting of the manuscript: Lumba-Brown, Yeates, Sarmiento, Breiding, Haegerich, Giza, Gioia, Benzel, Joseph, Broomand,

Suskauer, Weissman, Wright, Paulk, Wade, Halstead, Turner, Gronseth.

Critical revision of the manuscript for important intellectual content: Lumba-Brown, Yeates, Breiding, Gioia, Turner, Benzel,

Suskauer, Giza, Joseph, Broomand, Wright, Moser, McAvoy, Ewing-Cobbs, Duhaime, Putukian, Holshouser, Paulk, Wade, Herring,

Halstead, Keenan, Choe, Christian, Guskiewicz, Raksin, Gregory, Mucha, Taylor, Callahan, DeWitt, Collins, Kirkwood, Ragheb, Spinks, Ellenbogen, Ganiats, Hoffman, Getchius, Gronseth, Donnell, Timmons.

Statistical analysis: Lumba-Brown, Yeates, Joseph, Broomand, Weissman, Gioia, Gronseth. Administrative, technical, or material support: Sarmiento, Breiding, Haegerich, Sabelhaus, Hoffman, Getchius, Gronseth, Donnell.

Supervision: Sarmiento, Breiding, Getchius, Gronseth, Timmons. 
University of Florida Health Science Center, Jacksonville (Joseph); Center for Neuropsychological Services, Kaiser Permanente, Roseville, California (Broomand); Emory University School of Medicine, Atlanta, Georgia (Weissman, Wright); Icahn School of Medicine at Mount Sinai, New York, New York (Gordon); Sports Concussion Center of New Jersey, Princeton (Moser); Rocky Mountain Hospital for Children, Denver, Colorado (McAvoy); Children's Learning Institute, Department of Pediatrics, University of Texas (UT) Health Science Center at Houston (EwingCobbs); Massachusetts General Hospital, Harvard University, Boston (Duhaime); University Health Services, Princeton University, Princeton, New Jersey (Putukian); Loma Linda University Health, Loma Linda, California (Holshouser); Cincinnati Children's Hospital Medical Center, Cincinnati, Ohio (Wade); University of Washington School of Medicine, Seattle (Herring, Ellenbogen); St Louis Children's Hospital, St Louis, Missouri (Halstead); University of Utah, Salt Lake City (Keenan); Children's Hospital of Philadelphia, Raymond and Ruth Perelman School of Medicine, University of Pennsylvania, Philadelphia (Christian, Callahan); The University of North Carolina at Chapel Hill (Guskiewicz); John H. Stroger, Jr Hospital of Cook County (formerly Cook County Hospital), Chicago, Illinois (Raksin); Vanderbilt University School of Medicine, Nashville, Tennessee (Gregory); University of Pittsburgh Medical Center Sports Medicine Concussion Program, Pittsburgh, Pennsylvania (Mucha, Collins); Nationwide Children's Hospital Research Institute, Columbus, Ohio (Taylor); Jameson Crane Sports Medicine Institute, School of Health and Rehabilitation Sciences, The Ohio State University Wexner Medical Center, Columbus (DeWitt); Children's Hospital Colorado, Aurora (Kirkwood); Nicklaus Children's Hospital, University of Miami Miller School of Medicine, Miami, Florida (Ragheb); Department of Pediatric Neurosurgery, St Joseph's Children's Hospital, Tampa, Florida (Spinks); University of California, San Diego (Ganiats); Vanguard Communications, Washington, DC (Sabelhaus); The National Association of State EMS Officials, Washington, lowa (Altenhofen); Social Marketing Group, ICF, Rockville, Maryland (Hoffman, Donnell); American Academy of Neurology, Minneapolis, Minnesota (Getchius); University of Kansas Medical Center, Kansas City (Gronseth); University of Virginia School of Medicine, Charlottesville (O'Connor); Penn State University Milton S. Hershey Medical Center, Hershey, Pennsylvania (Timmons).

\section{Abstract}

IMPORTANCE-Mild traumatic brain injury (mTBI), or concussion, in children is a rapidly growing public health concern because epidemiologic data indicate a marked increase in the number of emergency department visits for mTBI over the past decade. However, no evidencebased clinical guidelines have been developed to date for diagnosing and managing pediatric mTBI in the United States.

OBJECTIVE-To provide a guideline based on a previous systematic review of the literature to obtain and assess evidence toward developing clinical recommendations for health care professionals related to the diagnosis, prognosis, and management/treatment of pediatric mTBI.

EVIDENCE REVIEW-The Centers for Disease Control and Prevention (CDC) National Center for Injury Prevention and Control Board of Scientific Counselors, a federal advisory committee, established the Pediatric Mild Traumatic Brain Injury Guideline Workgroup. The workgroup drafted recommendations based on the evidence that was obtained and assessed within the systematic review, as well as related evidence, scientific principles, and expert inference. This information includes selected studies published since the evidence review was conducted that were 
deemed by the workgroup to be relevant to the recommendations. The dates of the initial literature search were January 1, 1990, to November 30, 2012, and the dates of the updated literature search were December 1, 2012, to July 31, 2015.

FINDINGS-The CDC guideline includes 19 sets of recommendations on the diagnosis, prognosis, and management/treatment of pediatric mTBI that were assigned a level of obligation (ie, must, should, or may) based on confidence in the evidence. Recommendations address imaging, symptom scales, cognitive testing, and standardized assessment for diagnosis; history and risk factor assessment, monitoring, and counseling for prognosis; and patient/family education, rest, support, return to school, and symptom management for treatment.

CONCLUSIONS AND RELEVANCE-This guideline identifies the best practices for mTBI based on the current evidence; updates should be made as the body of evidence grows. In addition to the development of the guideline, $\mathrm{CDC}$ has created user-friendly guideline implementation materials that are concise and actionable. Evaluation of the guideline and implementation materials is crucial in understanding the influence of the recommendations.

Mild traumatic brain injury (mTBI), or concussion, in children is a significant public health concern. From 2005 to 2009, children made more than 2 million outpatient visits and almost 3 million emergency department (ED) visits for mTBI. ${ }^{1}$ In a subset of pediatric patients, postconcussive symptoms persist beyond 2 weeks and can continue for longer than 3 months. ${ }^{2}$ Pathophysiologic injury and symptoms (both acute and long-term) affect a child's ability to function physically, cognitively, and psychologically after mTBI. ${ }^{3-5}$

Consensus guidelines on the management of mTBI in adults have been developed. ${ }^{6,7}$ In 2013, evidence-based guidelines related to the management of sports-related concussion in children and adults were published, ${ }^{8}$ and the Ontario Neurotrauma Foundation ${ }^{9}$ published an evidence-based guideline for diagnosing and managing pediatric concussion in 2014. To date, no broad, evidence-based clinical guidelines have been developed in the United States for the purposes of diagnosis, prognosis, and management/treatment of pediatric mTBI. Clinical guidance for health care professionals is critical to improving the health and safety of this vulnerable population.

This guideline provides evidence-based recommendations for health care professionals that were developed using a rigorous scientific process based on a comprehensive review of pediatric mTBI scientific evidence. ${ }^{10}$ Recommendations aim to provide health care professionals in primary care, outpatient specialty, inpatient, and emergency care settings in the United States with evidence-based guidance on the diagnosis and management of mTBI in children 18 years and younger.

Although "concussion," "minor head injury," and mTBI are frequently used interchangeably, they have different connotations for families, researchers, and health care professionals, allowing for misinterpretation. ${ }^{1-15}$ Therefore, the guideline recommends the clinical use of the single term mild traumatic brain injury. In 2004, the World Health Organization Collaborating Centre Task Force on Mild Traumatic BrainInjury, ${ }^{15}$ alongside the Mild Traumatic Brain Injury Committee of the Head Injury Interdisciplinary Special Interest Group of the American Congress of Rehabilitation Medicine ${ }^{13}$ and the US Centers for 
Disease Control and Prevention (CDC) Mild Traumatic Brain Injury Working Group Report to Congress, ${ }^{14}$ defined mTBI as "an acute brain injury resulting from mechanical energy to the head from external physical forces including: (1) 1 or more of the following: confusion or disorientation, loss of consciousness for 30 minutes or less, post-traumatic amnesia for less than 24 hours, and/or other transient neurological abnormalities such as focal signs, symptoms, or seizure; (2) Glasgow Coma Scale score of 13-15 after 30 minutes post-injury or later upon presentation for healthcare."15(p7) A wide clinical and functional definition of pediatric mTBI was used for this guideline to be cognizant of the heterogeneity of presentations and outcomes of children with $\mathrm{mTBI}$ and to prevent the exclusion of children representing the more severe end of the mTBI spectrum. Specifically, pediatric patients were included with Glasgow Coma Scale (GCS) scores of 13 to 15 with or without the complication of intracranial injury (ICI) on neuroimaging and regardless of potentially requiring a hospital admission and/or neurosurgical intervention.

\section{Methods}

This guideline was based on a previous systematic review of the literature ${ }^{10}$ to obtain and assess evidence toward developing clinical recommendations for health care professionals related to the diagnosis, prognosis, and management/treatment of pediatric mTBI. The dates of the initial literature search were January 1, 1990, to November 30, 2012, and the dates of the updated literature search were December 1, 2012, to July 31, 2015. No institutional review board approval or participant informed consent was necessary.

\section{Federal Advisory Committee Process}

The CDC National Center for Injury Prevention and Control Board of Scientific Counselors (BSC), a federal advisory committee, established the Pediatric Mild Traumatic Brain Injury Guideline Workgroup to conduct a systematic review of the literature and draft clinical recommendations for health care professionals on the diagnosis, prognosis, and management/treatment of mTBI among children 18 years and younger. Before their participation and again near the end of the process, workgroup members and ad hoc experts were asked to disclose activities that could pose possible conflicts of interest. The CDC reviewed disclosed activities, and no conflicts of interest were identified. Furthermore, members of the BSC completed an Office of Government Ethics Form 450 to disclose relevant interests. Activities that did not pose a conflict but pertain to the topic of the guideline are disclosed. More information on the workgroup's activities can be found in the systematic review ${ }^{10}$ and the Pediatric Mild Traumatic Brain Injury Guideline Workgroup Report ("Workgroup Report"). ${ }^{16}$

\section{American Academy of Neurology Guideline}

The Pediatric Mild Traumatic Brain Injury Guideline Workgroup conducted a systematic review of the literature and drafted clinical recommendations using the methods developed by the American Academy of Neurology. ${ }^{17}$ The process included clinical question identification and a systematic review. The review methods and findings that support the recommendations are reported in detail in the systematic review ${ }^{10}$ accompanying the guideline. Evidence was rated as part of the systematic review using a modified Grading of 
Recommendations Assessment Development and Evaluation method. The workgroup drafted recommendations based on the systematic review, as well as related evidence, scientific principles, and expert inference, and categorized recommendations into 3 topic areas of the diagnosis, prognosis, and management/treatment of pediatric mTBI.

Clinical recommendations were collated and distributed among workgroup members in sequential rounds of voting to determine consensus. Workgroup members were presented with a series of potential recommendations and a rationale for each recommendation. The rationale was based on the research identified in the systematic review that was relevant to that recommendation (full rationales can be found in the Workgroup Report). ${ }^{16}$ Each workgroup member was requested to review and vote on all of the potential recommendations, and an $80 \%$ response was required for each recommendation before tabulation. After 4 rounds of voting, the workgroup achieved consensus on 46 clinical recommendations: 11 pertained to diagnosis, 12 were related to prognosis, and 23 focused on management/treatment. The Box describes how workgroup members assigned a level of confidence in the inference (ie, high, moderate, low, or very low) and a strength of recommendation (ie, level A, B, C, U, or R) for each recommendation. A more detailed description of the voting process, as well as summaries of the clinical evidence profile for each recommendation, are available in the eAppendix and the eTable in the Supplement. Using the Work-group Report, CDC grouped the 46 recommendations into 19 sets of recommendations on the diagnosis, prognosis, and management/treatment of pediatric mTBI that were assigned a level of obligation (ie, must, should, or may) based on confidence in the evidence and on clinical focus (eg, "General Health Care Provider Counseling of Prognosis" and "Cognitive Impairment Management/Treatment") and constructed a draft Guideline on the Diagnosis and Management of Mild Traumatic Brain Injury Among Children ("Guideline"). As coauthors of the guideline, workgroup members individually reviewed the full draft guideline before public comment and peer review.

\section{Public Comment and Peer Review}

To obtain comments from the public on the full draft guideline, the CDC published a notice in the Federal Register (82 FR §45588) announcing the availability of the guideline for public comment during a 60-day period on Regulations.gov (docket number CDC-20170089) from September 29 through November 28, 2017. In addition, public comments were received on the Workgroup Report during a BSC meeting open to the public. Because the guideline provides scientific information that could have a clear and substantial influence on public and private sector decisions, the guideline was peer reviewed per the final Office of Management and Budget information quality bulletin for peer review by 2 external, independent reviewers. The CDC carefully considered comments of the public and peer reviewers when developing and revising the guideline.

\section{Recommendations}

The guideline includes 19 sets of recommendations on the diagnosis, prognosis, and management/treatment of mTBI in children. A list of all of the recommendations is provided in the eTable in the Supplement. 


\section{Diagnostic Recommendations}

This section contains recommendations regarding the diagnostic utility of head imaging, symptom scales, cognitive testing, and serum biomarkers.

Risk Factors for ICl and Computed Tomography-Recommendation 1A: Health care professionals should not routinely obtain head computed tomography (CT) for diagnostic purposes in children with mTBI (moderate confidence in the inference ["moderate"]; strength of recommendation level B ["level B"]).

Recommendation 1B: Health care professionals should use validated clinical decision rules to identify children with mTBI at low risk for ICI in whom head CT is not indicated, as well as children who may be at higher risk for clinically important ICI and thus may warrant head CT. Existing decision rules, ${ }^{33}$ such as the Pediatric Emergency Care Applied Research Network (PECARN) decision rules, combine a variety of factors that, when assessed together, may increase the risk for more serious injury. Such risk factors include the following:

- $\quad$ Age younger than 2 years

- Vomiting

- Loss of consciousness

- $\quad$ Severe mechanism of injury

- $\quad$ Severe or worsening headache

- $\quad$ Amnesia

- Nonfrontal scalp hematoma

- Glasgow Coma Scale score less than 15

- $\quad$ Clinical suspicion for skull fracture (moderate; level B).

Recommendation $1 C$. For children diagnosed as having mTBI, health care professionals should discuss the risks of pediatric head CT in the context of risk factors for ICI with the patient and his/her family (moderate; level B).

Rationale: Up to $7.5 \%$ of children seen in the ED with mTBI will have ICI. ${ }^{18-32}$ Identification of risk factors for ICI in children initially seen with possible mTBI in the acute setting is important to the diagnosis of more severe forms of TBI, further directing observation and the possible need for emergent head CT. Intracranial injury further influences the prognosis of patients with mTBI (see the Prognosis Recommendations section). Moderate evidence indicates that several risk factors identify patients with increased risk of ICI. ${ }^{20,22,33-35}$ Generally, risk factors are not sufficiently predictive in isolation to guide clinical care (excluding GCS score and clinical suspicion for skull fracture). ${ }^{36-40}$

Instead, strong clinical evidence shows that the use of clinical decision rules that combine multiple risk factors are more effective in identifying children at low risk for ICI. ${ }^{20,22,33,35}$ 
The risks of ICI provided in this document were not separated by isolated findings versus multiple findings. In addition, some of the reported risks of ICI could be higher in these recommendations because of the inclusion of studies of mTBI with GCS scores of 13 to 15 . Head CT is the preferred diagnostic tool in acute care settings to rapidly identify ICI. However, higher doses of radiation attributable to this type of imaging in children have been associated in studies ${ }^{41-44}$ with an increase in the lifetime cancer risk, although the cumulative absolute risk appears small. Furthermore, certain pediatric populations will require sedation to obtain adequate neuroimaging, increasing the overall risk related to imaging processes. ${ }^{45}$ Families require clinical counseling regarding these risks to understand the best practices for the clinical care of their child. They should be aware that, after seemingly minor head injuries and mTBI, ICI resulting in clinically important outcomes, such as neurosurgical intervention, is rare. ${ }^{18-20,25-27,29,33,46-53}$ Clinical evaluation of the child with possible mTBI includes balancing the likelihood of potentially devastating complications of a more severe injury against the risks associated with head CT (as well as possible concomitant sedation for imaging).

Brain Magnetic Resonance Imaging-Recommendation 2: Health care professionals should not routinely use magnetic resonance imaging (MRI) in the acute evaluation of suspected or diagnosed mTBI (moderate; level B).

Rationale: No study met inclusion criteria addressing the use of brain MRI in the diagnosis of mTBI in children. An MRI is more sensitive in identifying structural abnormalities than $\mathrm{CT}, 54,55$ and MRI avoids the use of ionizing radiation associated with CT. Nevertheless, MRI more often requires sedation because of longer imaging acquisition times and is more expensive than CT; however, rapid-sequence MRI in nonsedated patients has recently been successfully used in children with suspected acute TBI. ${ }^{56}$

Single-Photon Emission CT-Recommendation 3: Health care professionals should not use single-photon emission CT (SPECT) in the acute evaluation of suspected or diagnosed mTBI (moderate; level B).

Rationale: The systematic review did not find any study that met our inclusion criteria addressing the use of SPECT in the diagnosis of mTBI in children. Furthermore, SPECT is not commonly used in the clinical setting of TBI in children, may require patient sedation, requires intravenous access in the child with the injection of a radiopharmaceutical, and may be more expensive than head $\mathrm{CT}$ alone because it is often used in conjunction with $\mathrm{CT}$.

Skull Radiograph—Recommendation $4 A$ : Skull radiographs should not be used in the diagnosis of pediatric mTBI (high; level B).

Recommendation $4 B$ : Skull radiographs should not be used in the screening for ICI (high; level B).

Rationale: The systematic review identified 2 class III studies ${ }^{19,57}$ evaluating the use of skull radiographs in children after minor head injury. One study ${ }^{19}$ identified a possible skull fracture in $7.1 \%$ (95\% CI, $4.0 \%-10.3 \%)$ of these patients. A radiograph is not the optimal 
test to diagnose skull fracture with ICI after mTBI for several reasons: specifically, the literature reports that skull radiographs have $63 \%$ sensitivity for diagnosing a single skull fracture in children; a radiograph cannot detect ICIs, such as hemorrhage, shift from midline, or edema; and radiographs use radiation for imaging. ${ }^{57}$ Clinical suspicion for skull fracture is a risk factor for ICI after mTBI in children. ${ }^{22,33-35}$ Head CT better detects ICIs and better characterizes skull fractures, making it the more appropriate diagnostic imaging choice when such imaging is clinically indicated.

\section{Neuropsychological Tools, Including Symptom Scales, Computerized Cognitive Testing, and Standardized Assessment of Concussion-}

Recommendation 5A: Health care professionals should use an age-appropriate, validated symptom rating scale as a component of the diagnostic evaluation in children seen with acute mTBI (moderate; level B).

Recommendation 5B: Health care professionals may use validated, age-appropriate computerized cognitive testing in the acute period of injury as a component of the diagnosis of mTBI (moderate; level C).

Recommendation 5C. The Standardized Assessment of Concussion should not be exclusively used to diagnose mTBI in children aged 6 to 18 years (moderate; level B).

Rationale: The consequences of missing a diagnosis of mTBI include failure to recommend appropriate treatment and management. In addition, an undiagnosed mTBI may contribute to the prolongation of symptoms and an increased risk of reinjury. The systematic review concluded that the Graded Symptom Checklist is useful in distinguishing children 6 years and older with mTBI from those without TBI within the first 2 days after injury. ${ }^{58}$ The review concluded that the Post Concussion Symptom Scale used in a computerized neurocognitive testing battery distinguishes high school athletes with mTBI from those without TBI within the first 4 days after injury. ${ }^{59,60}$ There are several other validated symptom scales that are reliable in the diagnosis of mTBI and have demonstrated validity at ages younger than high school (eg, the Health and Behavior Inventory ${ }^{61}$ and the PostConcussion Symptom Inventory ${ }^{62}$ ). Symptom rating scales can be applied quickly and inexpensively.

Two class II studies ${ }^{59,60}$ met inclusion criteria related to computerized cognitive testing and the diagnosis of mTBI in children. These studies specifically used a computerized neurocognitive testing battery and demonstrated that it probably distinguishes high school athletes with and without mTBI in the first 4 days after injury and may add sensitivity to the use of a symptom rating scale alone. ${ }^{59,60}$ While these 2 studies only reviewed 1 specific computerized neurocognitive battery, related evidence suggests that other validated computerized cognitive tests are also able to discriminate between children with and without mTBI. ${ }^{63,64}$

The systematic review demonstrated that cognitive screening using the Standardized Assessment of Concussion was not accurate in distinguishing those children with mTBI from those without mTBI because of lack of statistical significance from a single class III study. ${ }^{58}$ 
Serum Markers-Recommendation 6: Health care professionals should not use biomarkers outside of a research setting for the diagnosis of children with mTBI (high; level $\mathrm{R})$.

Rationale: There is insufficient evidence to currently recommend any of the studied biomarkers for the diagnosis of mTBI in children. In 2 class II studies, ${ }^{65,66} \mathrm{~S} 100 \mathrm{~B}$ was shown to be associated with a low sensitivity but high specificity in patients with severe TBI, with no discrimination in mild to moderate TBI. In a class II study ${ }^{65}$ tau protein levels were significantly different across pediatric patients with mTBI with normal head CT, those with abnormal CT, and among non-TBI controls. A single class II study 66 explored the use of autoantibodies against glutamate receptors and oxide metabolites as a marker to discriminate between severe and mTBI in children. There was good discrimination between the 2 groups; however, further data are needed. A single class III study ${ }^{67}$ examined multiplex bead array biomarkers in a small number of infants with TBI compared with controls and found significant differences in a number of biomarkers. Related studies ${ }^{68-71}$ have demonstrated associations between neuronal ubiquitin C-terminal hydrolase-L1 and glial fibrillary acidic protein biomarker levels and ICI in adults, and a single class II study ${ }^{72}$ of 23 children found insufficient evidence for the use of these biomarkers in distinguishing children with or without mTBI.

\section{Prognostic Recommendations}

This section contains recommendations related to counseling on prognosis, assessment of the premorbid history and cumulative risk, use of tools to track recovery, and interventions for patients with a poor prognosis.

General Health Care Professional Counseling of Prognosis-Recommendation $7 A$ : Health care professionals should counsel patients and families that most $(70 \%-80 \%)$ children with mTBI do not show significant difficulties that last more than 1 to 3 months after injury (moderate; level B).

Recommendation $7 B$ : Health care professionals should counsel patients and families that, although some factors predict an increased or decreased risk for prolonged symptoms, each child's recovery from mTBI is unique and will follow its own trajectory (moderate; level B).

Rationale: Recovery from pediatric mTBI is variable, ${ }^{73-75}$ and no single factor can predict symptom resolution or outcome. ${ }^{76}$ Symptoms experienced by most children with mTBI resolve within 1 to 3 months after injury. ${ }^{73}$ A single class III study ${ }^{77}$ reported that providing informational booklets to families that counseled on symptoms and coping strategies for children with mTBI resulted in improved patient outcomes at 3 months. Related studies 78,79 in children and adults with mTBI report direct patient benefits of counseling by health care professionals. Public health campaigns have emphasized the importance of parent and family education in mTBI because health outcomes in general are optimized through patient health literacy and the resulting behavior modifications. ${ }^{80-82}$ Important aspects of health care professional counseling are outlined in recommendation 12 . 
Prognosis Related to the Premorbid Conditions-Recommendation $8 A$ : Health care professionals should assess the premorbid history of children either before injury as a part of pre-participation athletic examinations or as soon as possible after injury in children with mTBI to assist in determining prognosis (moderate; level B).

Recommendation $8 B$ : Health care professionals should counsel children and families completing preparticipation athletic examinations and children with mTBI, as well as their families, that recovery from mTBI might be delayed in those with the following:

- $\quad$ Premorbid histories of mTBI

- Lower cognitive ability (for children with an intracranial lesion)

- Neurological or psychiatric disorder

- $\quad$ Learning difficulties

- Increased preinjury symptoms (ie, similar to those commonly referred to as "postconcussive")

- $\quad$ Family and social stressors (moderate; level B).

Rationale: Evidence of varying strength indicates that there is an increased risk of delayed recovery or prolonged symptoms associated with the premorbid conditions listed above in children with mTBI. ${ }^{83-89}$

Assessment of Cumulative Risk Factors and Prognosis-Recommendation 9A: Health care professionals should screen for known risk factors for persistent symptoms in children with mTBI (moderate; level B).

Recommendation 9B: Health care professionals may use validated prediction rules, which combine information about multiple risk factors for persistent symptoms, to provide prognostic counseling to children with mTBI evaluated in ED settings (high; level C).

Rationale: Evidence of varying strength indicates that a variety of noninjury (eg, demographic) and injury-related factors predict outcomes in pediatric mTBI. Specifically, symptoms may last longer among older children/adolescents, ${ }^{73,90,91}$ children of Hispanic race/ethnicity (compared with white race/ethnicity), ${ }^{91}$ children of lower socioeconomic status, ${ }^{89,91}$ children with more severe presentations of $\mathrm{mTBI}^{75,92,93}$ (including those associated with ICI), ${ }^{92,94}$ and children reporting more acute postconcussion symptoms. $74,84,95$ In addition, headaches persist longer in girls. ${ }^{90}$ However, no single factor is strongly predictive of outcome. Only 1 prediction rule has been validated to date. It is based on a 2016 study ${ }^{96}$ of 3063 children with mTBI seen in the ED and demonstrated that an empirically derived set of risk factors predicted the risk of persistent postconcussion symptoms at 28 days.

Assessment Tools and Prognosis-Recommendation 10A: Health care professionals should use a combination of tools to assess recovery in children with mTBI (moderate; level B). 
Recommendation 10B: Health care professionals should use validated symptom scales to assess recovery in children with mTBI (moderate; level B).

Recommendation 10C. Health care professionals may use validated cognitive testing (including measures of reaction time) to assess recovery in children with mTBI (moderate; level C).

Recommendation 10D: Health care professionals may use balance testing to assess recovery in adolescent athletes with mTBI (moderate; level C).

Rationale: No single assessment tool is strongly predictive of outcome in children with mTBI. ${ }^{76}$ However, multiple tools have shown utility in the assessment of individual patients and their recovery from mTBI. ${ }^{97-99}$ Symptom scales and cognitive testing (including measures of reaction time) have the strongest evidence in terms of their contribution to predicting outcomes and assessing recovery. ${ }^{100}$ Less evidence supports balance testing as a predictor for prognosis in children, but it has shown utility in older adolescent athletes. ${ }^{101}$

Interventions for mTBI With Poor Prognosis-Recommendation 11A: Health care professionals should closely monitor children with mTBI who are determined to be at high risk for persistent symptoms based on their premorbid history, demographics, and/or injury characteristics (high; level B).

Recommendation 11B: For children with mTBI whose symptoms do not resolve as expected with standard care (ie, within 4-6 weeks), health care professionals should provide or refer for appropriate assessments and/or interventions (moderate; level B).

Rationale: The symptoms experienced by most children with mTBI resolve within 1 to 3 months after injury, ${ }^{73}$ but some children are at risk for persistent symptoms and delayed recovery (ie, those who demonstrate certain premorbid characteristics and other risk factors [see recommendations 8 and 9]). Children with mTBI who are at high risk for persistent symptoms or delayed recovery are more likely to require intervention than children at low risk. Health care professionals can more effectively counsel patients with mTBI when they have assessed prognostic risk factors.

\section{Recommendations Related to Management/Treatment}

This section contains recommendations related to the provision of patient/family education, counseling related to physical/cognitive rest, assessment of patient psychosocial/emotional support, and managing a patient's return to school. In addition, this section contains recommendations related to the management/treatment of headache, vestibulo-oculomotor dysfunction, sleep problems, and cognitive impairment.

Patient/Family Education and Reassurance-Recommendation 12: In providing education and reassurance to the family, the health care professional should include the following information:

- Warning signs of more serious injury

- Description of injury and expected course of symptoms and recovery 
- Instructions on how to monitor postconcussive symptoms

- $\quad$ Prevention of further injury

- Management of cognitive and physical activity/rest

- Instructions regarding return to play/recreation and school

- Clear clinician follow-up instructions (high; level A).

Rationale: There is no definitive evidence to indicate that specific methods of patient and family education and reassurance after pediatric mTBI are associated with clear improvements in patient health outcomes. Regardless, public health campaigns have emphasized the importance of parent and family education in mTBI because health outcomes in general are optimized through health literacy and the resulting behavior modifications. ${ }^{80-82}$ Patient and family education and reassurance are key components of mTBI care initiatives and ED discharge instructions. ${ }^{77-79,102}$ Standardized processes of evaluation and discharge instruction provide significant benefit with respect to pediatric patient mTBI outcomes. ${ }^{78}$

Cognitive/Physical Rest and Aerobic Treatment-Recommendation 13A: Health care professionals should counsel patients to observe more restrictive physical and cognitive activity during the first several days after mTBI in children (moderate; level B).

Recommendation 13B: Following these first several days, health care professionals should counsel patients and families to resume a gradual schedule of activity that does not exacerbate symptoms, with close monitoring of symptom expression (number and severity) (moderate; level B).

Recommendation 13C: After the successful resumption of a gradual schedule of activity (see recommendation 13B), health care professionals should offer an active rehabilitation program of progressive reintroduction of noncontact aerobic activity that does not exacerbate symptoms, with close monitoring of symptom expression (number and severity) (high; level B).

Recommendation 13D: Health care professionals should counsel patients to return to full activity when they return to premorbid performance if they have remained symptom free at rest and with increasing levels of physical exertion (moderate; level B).

Rationale: Historically, "rest" has been a foundation in the treatment of acute mTBI. ${ }^{103,104}$ However, scientific evidence supporting its timing, duration, and efficacy is limited. ${ }^{105}$ Related evidence suggests that rest or reduction in cognitive/physical activity is beneficial immediately after mTBI and, for those who are slow to recover, may help accelerate recovery. ${ }^{106-108}$ The postinjury period is a posited temporal window of vulnerability for reinjury 109,110 because the reinjury threshold is lower during recovery and the symptom burden may be greater. ${ }^{11-113}$ On the other hand, studies ${ }^{114-117}$ in children and adults with prolonged symptoms beyond 4 weeks demonstrate that physical exercise, performed below symptom exacerbation, reduced postconcussive symptoms in active rehabilitation models. 
The optimal timing to initiate an aerobic program after pediatric mTBI has not been established, and only a limited number of studies ${ }^{114-116}$ have applied this treatment to patients with symptoms persisting past 4 weeks. Related evidence suggests that early rest (within the first 3 days of injury) may be beneficial ${ }^{103,118}$ but that inactivity beyond this period for most children may worsen their self-reported symptoms. ${ }^{119}$

Psychosocial/Emotional Support-Recommendation 14: Health care professionals may assess the extent and types of social support (ie, emotional, informational, instrumental, and appraisal) available to children with mTBI and emphasize social support as a key element in the education of caregivers and educators (moderate; level C).

Rationale: Social support has proved useful in promoting the recovery of persons with TBI, particularly those with cognitive deficits. ${ }^{113,120}$ Limited research with those who have experienced an mTBI demonstrates similar benefits. ${ }^{121,122}$ Direct, ancillary, and extrapolated evidence is strongly suggestive of the utility of social support in the management of mTBI.

Return to School-Recommendation 15A: To assist children returning to school after mTBI, medical and school-based teams should counsel the student and family regarding the process of gradually increasing the duration and intensity of academic activities as tolerated, with the goal of increasing participation without significantly exacerbating symptoms (moderate; level B).

Recommendation 15B: Return-to-school protocols should be customized based on the severity of postconcussion symptoms in children with mTBI as determined jointly by medical and school-based teams (moderate; level B).

Recommendation $15 C$. For any student with prolonged symptoms that interfere with academic performance, school-based teams should assess the educational needs of that student and determine the student's need for additional educational supports, including those described under pertinent federal statutes (eg, Individuals With Disabilities Education Act $\S 504)^{123}$ (high; level B).

Recommendation 15D: Postconcussion symptoms and academic progress in school should be monitored collaboratively by the student, family, health care professional(s), and school teams, who jointly determine what modifications or accommodations are needed to maintain an academic workload without significantly exacerbating symptoms (high; level B).

Recommendation 15E: The provision of educational supports should be monitored and adjusted on an ongoing basis by the school-based team until the student's academic performance has returned to preinjury levels (moderate; level B).

Recommendation 15F: For students who demonstrate prolonged symptoms and academic difficulties despite an active treatment approach, health care professionals should refer the child for a formal evaluation by a specialist in pediatric mTBI (moderate;levelB). 
Rationale: Return to school after mTBI must be carefully planned given the injury symptoms (eg, headaches and fatigue interfering with learning, greater problems concentrating on schoolwork, and difficulty taking notes) that can affect learning and performance. ${ }^{124,125}$ Limited evidence exists to guide the timing or progression of return to activity in relation to academic activities. ${ }^{119}$ Consensus-based recommendations for returning to school after mTBI attempt to minimize cognitive and physical overexertion, while encouraging a prompt return to school to avoid the deleterious effects of prolonged school absence. ${ }^{104}$ Return-to-school protocols affirm the need for continued collaboration among medical, school, and family systems to gradually adjust interventions and return the child to full participation without significant worsening of symptoms. ${ }^{104,124,126-129}$ The protocols target the student's symptoms as the focus of intervention, linking specific accommodations in efforts to limit symptom expression. Because postconcussive symptoms resolve at different rates in different children after mTBI, individualization of return-toschool programming is necessary. To protect their legal right to an appropriate education, children with mTBI who have a greater symptom burden and prolonged recoveries may require formal educational planning incorporating protections under federal statutes. ${ }^{123,130}$

Posttraumatic Headache Management/Treatment-Recommendation 16A: Health care professionals in the ED should clinically observe and consider obtaining a head CT in children seen with severe headache, especially when associated with other risk factors and worsening headache after mTBI, to evaluate for ICI requiring further management in accord with validated clinical decision-making rules (high; level B).

Recommendation 16B: Children undergoing observation periods for headache with acutely worsening symptoms should undergo emergent neuroimaging (high; level B).

Recommendation 16C: Health care professionals and caregivers should offer nonopioid analgesia (ie, ibuprofen or acetaminophen) to children with painful headache after acute mTBI but also provide counseling to the family regarding the risks of analgesic overuse, including rebound headache (moderate; level B).

Recommendation 16D: Health care professionals should not administer 3\% hypertonic saline to children with mTBI for treatment of acute headache outside of a research setting at this time (moderate; level R).

Recommendation 16E: Chronic headache after mTBI is likely to be multifactorial; therefore, health care professionals should refer children with chronic headache after mTBI for multidisciplinary evaluation and treatment, with consideration of analgesic overuse as a contributory factor (high; level B).

Rationale: Children seen with a headache, including worsening or severe headache, after mTBI with GCS scores of 13 to 15 are probably at moderate risk for ICI, as reflected by a risk difference of $1.9 \%$ (95\% CI, $0.1 \%-3.6 \%$ ) from 3 class I studies ${ }^{20,22,33}$ and 1 class II study. ${ }^{35}$ This evidence supports the contention that the risk of not identifying more severe forms of TBI manifesting as a progressive, severe headache in a child with or without other risk factors outweighs the risk of ionizing radiation. Risk of isolated severe headache after 
mTBI for ICI was not supported in a large study ${ }^{40}$ when GCS scores were 14 or above.

Painful headache in children requires intervention. Nonopioid analgesics, such as ibuprofen and acetaminophen, are often effective in treating headaches in children, and opioids are not generally recommended as therapy for headaches. ${ }^{62,131,132}$ Nonopioid analgesic overuse carries important risks of toxic effects and rebound headache. ${ }^{133}$ There is insufficient evidence to currently recommend the administration of $3 \%$ hypertonic saline as a treatment for acute headache after mTBI in children. Among children in the ED, a single class I study ${ }^{134}$ found that $3 \%$ hypertonic saline possibly decreases pain with headache immediately after administration but not at 3 days after intervention.

Vestibulo-Oculomotor Dysfunction Management/Treatment-Recommendation 17: Health care professionals may refer children with subjective or objective evidence of persistent vestibule-oculomotor dysfunction after mTBI to a program of vestibular rehabilitation (moderate; level C).

Rationale: A single class II study ${ }^{135}$ reported that vestibular and oculomotor dysfunction may contribute to the diagnosis of mTBI and longer symptom duration. Limited evidence suggests that early vestibulo-ocular and cervicovestibular physical therapy may be of benefit for patients seen with subjective reports (symptoms of dizziness) or objective physical examination findings. ${ }^{136-139}$

Sleep Management/Treatment-Recommendation 18A: Health care professionals should provide guidance on proper sleep hygiene methods to facilitate recovery from pediatric mTBI (moderate; level B).

Recommendation 18B: If sleep problems emerge or continue despite appropriate sleep hygiene measures, health care professionals may refer children with mTBI to a sleep disorder specialist for further assessment (moderate; level C).

Rationale: Receiving adequate sleep has been shown to facilitate health ${ }^{140}$ and, when not adequate, adversely affects medical conditions, including TBI. ${ }^{141-143}$ While limited evidence supports a recommendation for sleep hygiene specifically in children with mTBI, related evidence in adults with TBI indicates benefits, suggesting that the maintenance of appropriate sleep and the management of disrupted sleep may be a critical target of treatment for the child with mTBI. ${ }^{144-146}$

Cognitive Impairment Management/Treatment-Recommendation 19A: Health care professionals should attempt to determine the etiology of cognitive dysfunction within the context of other mTBI symptoms (moderate; level B).

Recommendation 19B: Health care professionals should recommend treatment for cognitive dysfunction that reflects its presumed etiology (high; level B).

Recommendation 19C. Health care professionals may refer children with persisting problems related to cognitive function for a formal neuropsychological evaluation to assist in determining the etiology and recommending targeted treatment (high; level C). 
Rationale: Cognitive impairment occurs after mTBI and includes the areas of attention, memory and learning, response speed, and aspects of executive functions. ${ }^{59,60,147,148}$ Cognitive impairment may be directly related to the pathology of the brain injury (ie, impaired neurotransmission) but may also reflect secondary effects of other symptoms (eg, ongoing headache pain, fatigue/low energy, and low frustration tolerance) that may produce a disruption in cognitive processing. Neuropsychological evaluations can assist in determining the etiology of cognitive impairment and directing treatment. ${ }^{148}$

\section{Conclusions}

The science of managing mTBI in children is rapidly evolving and expanding. This guideline identifies the best practices based on the current evidence for health care professionals in primary care, outpatient specialty, inpatient, and emergency care settings; updates may be made as the body of evidence grows. Suggestions related to key future directions for research are described in the systematic review ${ }^{10}$ that informed this guideline.

Equally as important as the development of this guideline is a multifaceted approach to its implementation. ${ }^{149,150}$ The CDC created user-friendly implementation materials ${ }^{151}$ that are concise and actionable. ${ }^{150}$ These materials include a screening tool, online training, and fact sheets. Patient discharge instructions, inclusive of a return-to-activity protocol, and symptom-based recovery tips were also created. ${ }^{152}$ The CDC will leverage its HEADS UP campaign (http://www.cdc.gov/HEADSUP) to support distribution of the guideline implementation materials through leading organizations and digital platforms (ie, web, mobile, and electronic health records). Partner organizations' efforts are critical to ensure sustainability of this effort nationwide. Finally, examining the effectiveness of the guideline and implementation materials is a research priority of the CDC's Injury Center ${ }^{153}$; evaluation is crucial for understanding the influence of the recommendations, both intended and unintended, and for revising future recommendations and implementation materials.

\section{Supplementary Material}

Refer to Web version on PubMed Central for supplementary material.

\section{Funding/Support:}

The CDC provided $100 \%$ of the funding for the supplemental evidence review tasks and meeting support.

\section{Appendix}

Conflict of Interest Disclosures: Dr Benzel reports receiving funding from the Orthopedic Research and Education Foundation. Dr Gioia reports receiving royalties for the Behavior Rating Inventory of Executive Function from Psychological Assessment Resources Inc. Dr Giza reports receiving fees as a consultant to the National Football League Neurological Care Program, National Hockey League Players' Association, National Hockey League, Major League Soccer, National Basketball Association, US Soccer Federation, and the National Collegiate Athletic Association; medicolegal work on 1 or 2 cases annually; and research support from the National Football League and General Electric. Dr Halstead 
reports being a lead author on the American Academy of Pediatrics policy statement on concussion. Dr Herring reports past service on a medical advisory board for X2Biosystems and payment from Vicis, a helmet manufacturer. Dr Turner reports receiving financial support from Medtronic Corporation and NICO Corporation. Dr Wright reports receiving speaker and consultant fees from Astrocyte Pharmaceuticals Inc (Scientific Advisory Board), LPath Inc, and Biogen Inc, and receiving commercial support from Astrocyte Pharmaceuticals Inc, LPath, and OneMind. Dr Choe reports serving as a consultant for the World Boxing Council, USA Swimming, and Neural Analytics. Dr Christian reports serving as a medical-legal expert in child abuse cases. Dr Collins reports Board Membership and role as codeveloper for ImPACT applications; he also serves as a consultant to the Pittsburgh Steelers and Pittsburgh Penguins, and he reports medical-legal work as an expert on mTBI cases. Dr Ellenbogen reports participating in General Electric scientific board review. Dr Mucha reports receiving speaker fees from American Physical Therapy Association, Medbridge Education, Impact Applications, and several healthcare organizations. Dr Paulk reports receiving fees for legal consulting for a Pennsylvania practice. Dr Putukian reports working as a consultant for the USA Football Medical Advisory Committee, National Football League Head Neck and Spine Committee, US Lacrosse Sports Science \& Safety Committee, National Collegiate Athletics Association Concussion Task Force, and the US Soccer medical advisory committee and serving as a medical consultant for Major League Soccer; she also reports receiving a research grant support from the National Collegiate Athletics Association-Department of Defense Grand Alliance and the National Operating Committee on Standards for Athletic Equipment. Drs Gronesth, Getchius, Hoffman, and Donnell were compensated through a contract with the CDC (200-2007-20003 [019]) for their contributions to this study. No other disclosures were reported.

Role of the Funder/Sponsor: The CDC authors did not assist with the Pediatric Mild Traumatic Brain Injury Guideline Workgroup Report ("Workgroup Report"), ${ }^{16}$ including conduct of the study and collection, management, analysis, and interpretation of the data. The CDC authors had a role in preparation, review, and approval of the present guideline and decision to submit the manuscript for publication.

Additional Contributions: We thank Sally Schoessler, MEd, BSN, RN, National Association of School Nurses, for her assistance with the literature review, K. Alix Hayden, MLIS, MSc, PhD, University of Calgary, as well as Andrea L. Ball, MLS, MSIM, Linda Sabelhaus, MLS, and Nicole Vetter, MLIS, all of ICF, for their contributions to the comprehensive literature search. Ms Ball, Ms Sabelhaus, and Ms Vetter were compensated through a contract with the CDC (200-2007-20003 [019]) for their contributions.

Additional Information: The following individuals are members or ad-hoc experts of the CDC Pediatric mTBI Guideline Workgroup: Chair: Shelly D. Timmons, MD, PhD; Workgroup 4 Members and Ad-Hoc Experts: Katrina Altenhofen, MPH, Paramedic, CME, CCPSTI; Edward C. Benzel, MD; Catherine Broomand, PhD, ABPP-CN; James M. Callahan, MD; Meeryo C. Choe, MD; Cindy W. Christian, MD; Michael W. Collins, PhD; John DeWitt, PT, DPT, SCS, ATC; Ann-Christine Duhaime, MD; Richard G. Ellenbogen, MD; Linda Ewing-Cobbs, PhD; Theodore G. Ganiats, MD; Gerard A. Gioia, PhD; Christopher C. Giza, MD; Wayne A. Gordon, PhD, ABPP/Cn; Andrew Gregory, MD; Kevin 
Guskiewicz, PhD, ATC; Mark E. Halstead, MD; Stanley A. Herring, MD; Barbara

Holshouser, PhD; Madeline Matar Joseph, MD; Heather T. Keenan, MDCM, MPH, PhD; Michael W. Kirkwood, PhD, ABPP/CN; Angela Lumba-Brown, MD; Karen McAvoy, PsyD; Rosemarie Scolaro Moser, PhD, ABN, ABPP-RP; Anne Mucha, PT, DPT, MS, NCS; Robert E. O'Conner, MD; David Paulk, PA-C, EdD, DFAAPA (Dr Paulk is a survivor of traumatic brain injury); Margot Putukian, MD; John Ragheb, MD; P. B. Raksin, MD; Linda J.

Sabelhaus, MLS; Sally Schoessler, MEd, BSN, RN; T. J. Spinks, MD; Stacy Suskauer, MD; H. Gerry Taylor, PhD; Michael Turner, MD; Shari L. Wade, PhD; Barbara Weissman, MD; David W. Wright, MD; Keith Owen Yeates, PhD. CDC Pediatric mTBI Guideline Workgroup federal representatives: A. Cate Miller, PhD; Deborah Hirtz, MD; Elizabeth A. Edgerton, MD, MPH; James Kelly, MD; Jason Goldsmith, PhD; Therese A. West, DNP, APN, BC. The following individuals are members of the CDC National Center for Injury Prevention and Control Board of Scientific Counselors. Chair: Stephen W. Hargarten, MD, MPH; Members: John P. Allegrante, PhD, Joan Marie Duwve, MD, Samuel Forjuoh, MD, MPH, DrPH, FGCP, Gerard Anthony Gioia, PhD, Deborah Gorman-Smith, PhD, Traci Craig Green, PhD, Angela Denise Mickalide, PhD, MCHES, Sherry Davis Molock, PhD, Christina A. Porucznik, PhD, MSPH, Jay G. Silverman, PhD, Maria Testa, PhD, Shelly D. Timmons, MD, PhD; Ex-Officio Members: Melissa Lim Brodowski, PhD, Dawn Castillo, MPH, Wilson M. Compton, MD, MPE, Elizabeth A. Edgerton, MD, MPH, Thomas E. Feucht, PhD, Meredith A. Fox, PhD, Holly Hedegaard, MD, MSPH, John Howard, MD, Calvin C. Johnson, PhD, Lyndon J.O. Joseph, PhD, Jinhee J. Lee, PharmD, Iris Mabry-Hernandez, MD, MPH, Valerie Maholmes, PhD, Angela M. Moore Parmley, PhD, Thomas John Schroeder, MS, Kelly M. Taylor, MS, REHS, and Maria E. Vegega, PhD.

\section{REFERENCES}

1. Mannix R, O'Brien MJ, Meehan WP III. The epidemiology of outpatient visits for minor head injury: 2005 to 2009. Neurosurgery. 2013; 73(1):129-134. doi:10.1227/01.neu. 0000429846.14579.41 [PubMed: 23615100]

2. Babcock L, Byczkowski T, Wade SL, Ho M, Mookerjee S, Bazarian JJ. Predicting postconcussion syndrome after mild traumatic brain injury in children and adolescents who present to the emergency department. JAMA Pediatr. 2013;167(2):156-161. doi:10.1001/jamapediatrics.2013.434 [PubMed: 23247384]

3. Lee H, Wintermark M, Gean AD, Ghajar J, Manley GT, Mukherjee P. Focal lesions in acute mild traumatic brain injury and neurocognitive outcome: CT versus 3T MRI. J Neurotrauma. 2008;25(9): 1049-1056. doi:10.1089/neu.2008.0566 [PubMed: 18707244]

4. Hessen E, Nestvold K. Indicators of complicated mild TBI predict MMPI-2 scores after 23 years. Brain Inj. 2009;23(3):234-242. doi:10.1080/02699050902748349 [PubMed: 19205960]

5. Dikmen S, Machamer J, Fann JR, Temkin NR. Rates of symptom reporting following traumatic brain injury. J Int Neuropsychol Soc. 2010;16(3): 401-411. doi:10.1017/S1355617710000196 [PubMed: 20188017]

6. Jagoda AS, Bazarian JJ, Bruns JJ Jr, et al.; American College of Emergency Physicians; Centers for Disease Control and Prevention. Clinical policy: neuroimaging and decisionmaking in adult mild traumatic brain injury in the acute setting. Ann Emerg Med. 2008;52(6):714-748. doi:10.1016/ j.annemergmed.2008.08.021 [PubMed: 19027497]

7. Marshall S, Bayley M, McCullagh S, Velikonja D, Berrigan L. Clinical practice guidelines for mild traumatic brain injury and persistent symptoms. Can Fam Physician. 2012;58(3):257-267, e128e140. [PubMed: 22518895] 
8. American Academy of Neurology website. Sports concussion resources. https://www.aan.com/toolsand-resources/practicing-neurologists-administrators/patient-resources/sports-concussion-resources. Accessed March 12, 2018.

9. Zemek R, Duval S, Dematteo C, et al. Guidelines for Diagnosing and Managing Pediatric Concussion: Recommendations for Health Care Professionals. Toronto, Ontario, Canada: Ontario Neurotrauma Foundation; 2014.

10. Lumba-Brown A, Yeates KO, Sarmiento K, et al. Centers for Disease Control and Prevention guideline on the diagnosis and management of mild traumatic brain injury among children [published online September 4, 2018]. JAMA Pediatr. doi:10.1001/jamapediatrics.2018.2847

11. Dematteo CA, Hanna SE, Mahoney WJ, et al. "My child doesn't have a brain injury, he only has a concussion." Pediatrics. 2010;125(2):327-334. doi:10.1542/peds.2008-2720 [PubMed: 20083526]

12. Gordon KE, Dooley JM, Fitzpatrick EA, Wren P, Wood EP. Concussion or mild traumatic brain injury: parents appreciate the nuances of nosology. Pediatr Neurol. 2010;43(4):253-257. doi: 10.1016/j.pediatrneurol.2010.05.012 [PubMed: 20837303]

13. Mild Traumatic Brain Injury Committee of the Head Injury Interdisciplinary Special Interest Group of the American Congress of Rehabilitation Medicine. Definition of mild traumatic brain injury. J Head Trauma Rehabil. 1993;8(3):86-87. doi:10.1016/j.annemergmed.2006.08.032

14. National Center for Injury Prevention and Control. Report to Congress on Mild Traumatic Brain Injury in the United States: Steps to Prevent a Serious Public Health Problem. Atlanta, GA: Centers for Disease Control and Prevention; 2003 http://www.cdc.gov/traumaticbraininjury/pdf/ mtbireport-a.pdf. Accessed February 14, 2018.

15. Carroll LJ, Cassidy JD, Holm L, Kraus J, Coronado VG; WHO Collaborating Centre Task Force on Mild Traumatic Brain Injury. Methodological issues and research recommendations for mild traumatic brain injury: the WHO Collaborating Centre Task Force on Mild Traumatic Brain Injury. J Rehabil Med. 2004;(43 suppl):113-125. doi:10.1080/16501960410023877 [PubMed: 15083875]

16. Centers for Disease Control and Prevention. Report from the Pediatric Mild Traumatic Brain Injury Guideline Workgroup: systematic review and clinical recommendations for healthcare providers on the diagnosis and management of mild traumatic brain injury among children. https:// www.cdc.gov/injury/pdfs/bsc/systemicreviewcompilation_august_2016.pdf. Accessed February $15,2018$.

17. Gronseth GS, Woodroffe LM, Getchius TSD. Clinical Practice Guideline Process Manual. St Paul, MN: American Academy of Neurology; 2011.

18. Fabbri A, Servadei F, Marchesini G, Raggi A, Vandelli A. Analysis of different decision aids for clinical use in pediatric head injury in an emergency department of a general hospital. J Trauma. 2011;70 (5):E79-E83. doi:10.1097/TA.0b013e3181d4885a [PubMed: 20495492]

19. Boran BO, Boran P, Barut N, Akgun C, Celikoglu E, Bozbuga M. Evaluation of mild head injury in a pediatric population. Pediatr Neurosurg. 2006;42(4):203-207. doi:10.1159/000092355 [PubMed: 16714859]

20. Osmond MH, Klassen TP, Wells GA, et al.; Pediatric Emergency Research Canada (PERC) Head Injury Study Group. CATCH: a clinical decision rule for the use of computed tomography in children with minor head injury. CMAJ. 2010;182(4):341-348. doi:10.1503/cmaj.091421 [PubMed: 20142371]

21. Dietrich AM, Bowman MJ, Ginn-Pease ME, Kosnik E, King DR. Pediatric head injuries: can clinical factors reliably predict an abnormality on computed tomography? Ann Emerg Med. 1993; 22(10):1535-1540. doi:10.1016/S0196-0644(05)81254-5 [PubMed: 8214831]

22. Palchak MJ, Holmes JF, Vance CW, et al. A decision rule for identifying children at low risk for brain injuries after blunt head trauma. Ann Emerg Med. 2003;42(4):492-506. doi:10.1067/ S0196-0644(03)00425-6 [PubMed: 14520320]

23. Atabaki SM, Stiell IG, Bazarian JJ, et al. A clinical decision rule for cranial computed tomography in minor pediatric head trauma. Arch Pediatr Adolesc Med. 2008;162(5):439-445. doi:10.1001/ archpedi.162.5.439 [PubMed: 18458190]

24. Chan HC, Aasim WA, Abdullah NM, et al. Characteristics and clinical predictors of minor head injury in children presenting to two Malaysian accident and emergency departments. Singapore Med J. 2005;46(5):219-223. [PubMed: 15858690] 
25. Schunk JE, Rodgerson JD, Woodward GA. The utility of head computed tomographic scanning in pediatric patients with normal neurologic examination in the emergency department. Pediatr Emerg Care. 1996;12(3):160-165. doi:10.1097/00006565-199606000-00004 [PubMed: 8806136]

26. Davis RL, Mullen N, Makela M, Taylor JA, Cohen W, Rivara FP. Cranial computed tomography scans in children after minimal head injury with loss of consciousness. Ann Emerg Med. 1994;24(4): 640-645. doi:10.1016/S0196-0644(94)70273-X [PubMed: 8092590]

27. Simon B, Letourneau P, Vitorino E, McCall J. Pediatric minor head trauma: indications for computed tomographic scanning revisited. J Trauma. 2001;51(2):231-237. doi: 10.1097/00005373-200108000-00004 [PubMed: 11493779]

28. Fundarò C, Caldarelli M, Monaco S, et al. Brain CT scan for pediatric minor accidental head injury: an Italian experience and review of literature. Childs Nerv Syst. 2012;28(7):1063-1068. doi:10.1007/s00381-012-1717-9 [PubMed: 22349902]

29. Bramley H, Mcfarland C, Lewis MM, et al. Short-term outcomes of sport- and recreation-related concussion in patients admitted to a pediatric trauma service. Clin Pediatr (Phila). 2014;53(8):784790. doi:10.1177/0009922814533403 [PubMed: 24790025]

30. Gülşen I, Ak H, Karadaş S, Demır I, Bulut MD, Yaycioğlu S. Indications of brain computed tomography scan in children younger than 3 years of age with minor head trauma. Emerg Med Int. 2014;2014:248967. doi:10.1155/2014/248967 [PubMed: 24724031]

31. Katirci Y, Ocak T, Karamercan MA, et al. Compliance with CATCH rules in administering computerized tomography scans to children admitted to the emergency department with minor head trauma. Acta Med Mediter. 2013;29:717-722. http://www.actamedicamediterranea.com/ archive/2013/medica-4/compliance-with-catch-rules-in-administering-computerized-tomographyscans-to-children-admitted-to-the-emergency-department-with-minor-head-trauma. Accessed July 27, 2018.

32. Dunning J, Daly JP, Lomas JP, Lecky F, Batchelor J, Mackway-Jones K; Children's Head Injury Algorithm for the Prediction of Important Clinical Events Study Group. Derivation of the Children's Head Injury Algorithm for the Prediction of Important Clinical Events decision rule for head injury in children. Arch Dis Child. 2006;91(11): 885-891. doi:10.1136/adc.2005.083980 [PubMed: 17056862]

33. Kuppermann N, Holmes JF, Dayan PS, et al.; Pediatric Emergency Care Applied Research Network (PECARN). Identification of children at very low risk of clinically-important brain injuries after head trauma: a prospective cohort study. Lancet. 2009;374(9696):1160-1170. doi: 10.1016/S0140-6736(09)61558-0 [PubMed: 19758692]

34. Greenes DS, Schutzman SA. Clinical significance of scalp abnormalities in asymptomatic headinjured infants. Pediatr Emerg Care. 2001;17 (2):88-92. doi:10.1097/00006565-200104000-00002 [PubMed: 11334100]

35. Sun BC, Hoffman JR, Mower WR. Evaluation of a modified prediction instrument to identify significant pediatric intracranial injury after blunt head trauma. Ann Emerg Med. 2007;49(3):325332, 332.e1. doi:10.1016/j.annemergmed.2006.08.032 [PubMed: 17210207]

36. Dayan PS, Holmes JF, Atabaki S, et al.; Traumatic Brain Injury Study Group of the Pediatric Emergency Care Applied Research Network (PECARN). Association of traumatic brain injuries with vomiting in children with blunt head trauma. Ann Emerg Med. 2014;63(6):657-665. doi: 10.1016/j.annemergmed.2014.01.009 [PubMed: 24559605]

37. Nigrovic LE, Lee LK, Hoyle J, et al.; Traumatic Brain Injury (TBI) Working Group of Pediatric Emergency Care Applied Research Network (PECARN). Prevalence of clinically important traumatic brain injuries in children with minor blunt head trauma and isolated severe injury mechanisms. Arch Pediatr Adolesc Med. 2012;166 (4):356-361. doi:10.1001/archpediatrics. 2011.1156 [PubMed: 22147762]

38. Lee LK, Monroe D, Bachman MC, et al.; Traumatic Brain Injury (TBI) Working Group of Pediatric Emergency Care Applied Research Network (PECARN). Isolated loss of consciousness in children with minor blunt head trauma. JAMA Pediatr. 2014;168(9):837-843. doi:10.1001/ jamapediatrics.2014.361 [PubMed: 25003654]

39. Nishijima DK, Holmes JF, Dayan PS, Kuppermann N. Association of a guardian's report of a child acting abnormally with traumatic brain injury after minor blunt head trauma. JAMA Pediatr. 2015;169(12):1141-1147. doi:10.1001/jamapediatrics.2015.2743 [PubMed: 26502172] 
40. Dayan PS, Holmes JF, Hoyle J Jr, et al.; Pediatric Emergency Care Applied Research Network (PECARN). Headache in traumatic brain injuries from blunt head trauma. Pediatrics. 2015;135(3): 504-512. doi:10.1542/peds.2014-2695 [PubMed: 25647678]

41. Berrington de Gonzalez A, Salotti JA, McHugh K, et al. Relationship between paediatric CT scans and subsequent risk of leukaemia and brain tumours: assessment of the impact of underlying conditions. Br J Cancer. 2016;114(4):388-394. doi:10.1038/bjc.2015.415 [PubMed: 26882064]

42. Journy N, Ancelet S, Rehel JL, et al. Predicted cancer risks induced by computed tomography examinations during childhood, by a quantitative risk assessment approach. Radiat Environ Biophys. 2014;53(1):39-54. doi:10.1007/s00411-013-0491-8 [PubMed: 24105448]

43. Pearce MS, Salotti JA, Little MP, et al. Radiation exposure from CT scans in childhood and subsequent risk of leukaemia and brain tumours: a retrospective cohort study. Lancet. 2012;380 (9840):499-505. doi:10.1016/S0140-6736(12)60815-0 [PubMed: 22681860]

44. Miglioretti DL, Johnson E, Williams A, et al. The use of computed tomography in pediatrics and the associated radiation exposure and estimated cancer risk. JAMA Pediatr. 2013;167(8):700-707. doi:10.1001/jamapediatrics.2013.311 [PubMed: 23754213]

45. Moro-Sutherland DM, Algren JT, Louis PT, Kozinetz CA, Shook JE. Comparison of intravenous midazolam with pentobarbital for sedation for head computed tomography imaging. Acad Emerg Med. 2000;7(12):1370-1375. doi:10.1111/j.1553-2712.2000.tb00494.x [PubMed: 11099427]

46. Halley MK, Silva PD, Foley J, Rodarte A. Loss of consciousness: when to perform computed tomography? Pediatr Crit Care Med. 2004;5(3): 230-233. doi:10.1097/01.PCC. 0000123543.40224.73 [PubMed: 15115559]

47. Quayle KS, Jaffe DM, Kuppermann N, et al. Diagnostic testing for acute head injury in children: when are head computed tomography and skull radiographs indicated? Pediatrics. 1997;99(5):E11. doi:10.1542/peds.99.5.e11

48. Melo JR, Lemos-Júnior LP, Reis RC, et al. Do children with Glasgow 13/14 could be identified as mild traumatic brain injury? Arq Neuropsiquiatr. 2010;68(3):381-384. doi:10.1590/ S0004-282X2010000300010 [PubMed: 20602040]

49. Bainbridge J, Khirwadkar H, Hourihan MD. Vomiting: is this a good indication for CT head scans in patients with minor head injury? Br J Radiol. 2012;85(1010):183-186. doi:10.1259/bjr/ 56169980 [PubMed: 21937615]

50. Bressan S, Steiner IP, Mion T, Berlese P, Romanato S, Da Dalt L. The Pediatric Emergency Care Applied Research Network intermediate-risk predictors were not associated with scanning decisions for minor head injuries. Acta Paediatr. 2015;104(1):47-52. doi:10.1111/apa.12797 [PubMed: 25178836]

51. Schonfeld D, Fitz BM, Nigrovic LE. Effect of the duration of emergency department observation on computed tomography use in children with minor blunt head trauma. Ann Emerg Med. 2013;62(6): 597-603. doi:10.1016/j.annemergmed.2013.06.020 [PubMed: 23910481]

52. Zhu H, Gao Q, Xia X, Xiang J, Yao H, Shao J. Clinically-important brain injury and CT findings in pediatric mild traumatic brain injuries: a prospective study in a Chinese reference hospital. Int J Environ Res Public Health. 2014;11(4):3493-3506. doi:10.3390/ijerph110403493 [PubMed: 24675642]

53. Hamilton M, Mrazik M, Johnson DW. Incidence of delayed intracranial hemorrhage in children after uncomplicated minor head injuries. Pediatrics. 2010;126(1):e33-e39. doi:10.1542/peds. 2009-0692 [PubMed: 20566618]

54. Currie S, Saleem N, Straiton JA, Macmullen-Price J, Warren DJ, Craven IJ. Imaging assessment of traumatic brain injury. Postgrad Med J. 2016;92(1083):41-50. doi:10.1136/ postgradmedj-2014-133211 [PubMed: 26621823]

55. Kim JJ, Gean AD. Imaging for the diagnosis and management of traumatic brain injury. Neurotherapeutics. 2011;8(1):39-53. doi:10.1007/s13311-010-0003-3 [PubMed: 21274684]

56. Young JY, Duhaime AC, Caruso PA, Rincon SP. Comparison of non-sedated brain MRI and CT for the detection of acute traumatic injury in children 6 years of age or less. Emerg Radiol. 2016;23(4): 325-331. doi:10.1007/s10140-016-1392-3 [PubMed: 27166965] 
57. Mulroy MH, Loyd AM, Frush DP, Verla TG, Myers BS, Bass CR. Evaluation of pediatric skull fracture imaging techniques. Forensic Sci Int. 2012; 214(1-3):167-172. doi:10.1016/j.forsciint. 2011.07.050 [PubMed: 21880443]

58. Grubenhoff JA, Kirkwood M, Gao D, Deakyne S, Wathen J. Evaluation of the standardized assessment of concussion in a pediatric emergency department. Pediatrics. 2010;126(4):688-695. doi:10.1542/peds.2009-2804 [PubMed: 20819901]

59. Lovell MR, Collins MW, Iverson GL, et al. Recovery from mild concussion in high school athletes. J Neurosurg. 2003;98(2):296-301. doi:10.3171/jns.2003.98.2.0296 [PubMed: 12593614]

60. Schatz P, Pardini JE, Lovell MR, Collins MW, Podell K. Sensitivity and specificity of the ImPACT Test Battery for concussion in athletes. Arch Clin Neuropsychol. 2006;21(1):91-99. doi:10.1016/ j.acn.2005.08.001 [PubMed: 16143492]

61. Gioia GA, Schneider JC, Vaughan CG, Isquith PK. Which symptom assessments and approaches are uniquely appropriate for paediatric concussion? Br J Sports Med. 2009;43(suppl 1):i13-i22. doi:10.1136/bjsm.2009.058255 [PubMed: 19433419]

62. Institute of Medicine and National Research Council. In: Graham R, Rivara FP, Ford MA, Spicer CM, eds. Sports-Related Concussions in Youth: Improving the Science, Changing the Culture. Washington, DC: National Academies Press; 2014. doi:10.17226/18377.

63. Nelson LD, LaRoche AA, Pfaller AY, et al. Prospective, head-to-head study of three computerized neurocognitive assessment tools (CNTs): reliability and validity for the assessment of sport-related concussion. J Int Neuropsychol Soc. 2016;22(1):24-37. doi:10.1017/S1355617715001101 [PubMed: 26714883]

64. Berger RP, Pierce MC, Wisniewski SR, Adelson PD, Kochanek PM. Serum S100B concentrations are increased after closed head injury in children: a preliminary study. J Neurotrauma. 2002;19(11):1405-1409. doi:10.1089/089771502320914633 [PubMed: 12490005]

65. Geyer C, Ulrich A, Gräfe G, Stach B, Till H. Diagnostic value of S100B and neuron-specific enolase in mild pediatric traumatic brain injury. J Neurosurg Pediatr. 2009;4(4):339-344. doi: 10.3171/2009.5.PEDS08481 [PubMed: 19795965]

66. Sorokina EG, Semenova ZhB, Bazarnaya NA, et al. Autoantibodies to glutamate receptors and products of nitric oxide metabolism in serum in children in the acute phase of craniocerebral trauma. Neurosci Behav Physiol. 2009;39(4):329-334. doi:10.1007/s11055-009-9147-1 [PubMed: 19340572]

67. Berger RP, Ta'asan S, Rand A, Lokshin A, Kochanek P. Multiplex assessment of serum biomarker concentrations in well-appearing children with inflicted traumatic brain injury. Pediatr Res. 2009;65(1):97-102. doi:10.1203/PDR.0b013e31818c7e27 [PubMed: 18787505]

68. Papa L, Brophy GM, Welch RD, et al. Time course and diagnostic accuracy of glial and neuronal blood biomarkers GFAP and UCH-L1 in a large cohort of trauma patients with and without mild traumatic brain injury. JAMA Neurol. 2016;73(5): 551-560. doi:10.1001/jamaneurol.2016.0039 [PubMed: 27018834]

69. Papa L, Lewis LM, Silvestri S, et al. Serum levels of ubiquitin C-terminal hydrolase distinguish mild traumatic brain injury from trauma controls and are elevated in mild and moderate traumatic brain injury patients with intracranial lesions and neurosurgical intervention. J Trauma Acute Care Surg. 2012;72(5):1335-1344. doi:10.1097/TA.0b013e3182491e3d [PubMed: 22673263]

70. Kou Z, Gattu R, Kobeissy F, et al. Combining biochemical and imaging markers to improve diagnosis and characterization of mild traumatic brain injury in the acute setting: results from a pilot study. PLoS One. 2013;8(11):e80296. doi:10.1371/journal.pone.0080296 [PubMed: 24260364]

71. Welch RD, Ayaz SI, Lewis LM, et al. Ability of serum glial fibrillary acidic protein, ubiquitin Cterminal hydrolase-L1, and S100B to differentiate normal and abnormal head computed tomography findings in patients with suspected mild or moderate traumatic brain injury. $\mathrm{J}$ Neurotrauma. 2016;33(2):203-214. doi:10.1089/neu.2015.4149 [PubMed: 26467555]

72. Babcock L, McClanahan N, Ho ML. Uchl-1 and Gfap: are these promising acute diagnostic biomarkers for children with mild traumatic brain injury? Paper presented at: American Academy of Pediatrics; October 25, 2013; Orlando, FL. 
73. Barlow KM, Crawford S, Stevenson A, Sandhu SS, Belanger F, Dewey D. Epidemiology of postconcussion syndrome in pediatric mild traumatic brain injury. Pediatrics. 2010;126(2):e374e381. doi:10.1542/peds.2009-0925 [PubMed: 20660554]

74. Babikian T, Satz P, Zaucha K, Light R, Lewis RS, Asarnow RF. The UCLA longitudinal study of neurocognitive outcomes following mild pediatric traumatic brain injury. J Int Neuropsychol Soc. 2011; 17(5):886-895. doi:10.1017/S1355617711000907 [PubMed: 21813031]

75. Yeates KO, Taylor HG, Rusin J, et al. Longitudinal trajectories of postconcussive symptoms in children with mild traumatic brain injuries and their relationship to acute clinical status. Pediatrics. 2009;123(3):735-743. doi:10.1542/peds.2008-1056 [PubMed: 19254996]

76. Zemek RL, Farion KJ, Sampson M, McGahern C. Prognosticators of persistent symptoms following pediatric concussion: a systematic review. JAMA Pediatr. 2013;167(3):259-265. doi: 10.1001/2013.jamapediatrics.216 [PubMed: 23303474]

77. Ponsford J, Willmott C, Rothwell A, et al. Impact of early intervention on outcome after mild traumatic brain injury in children. Pediatrics. 2001; 108(6):1297-1303. doi:10.1542/peds. 108.6.1297 [PubMed: 11731651]

78. Zuckerbraun NS, Atabaki S, Collins MW, Thomas D, Gioia GA. Use of modified acute concussion evaluation tools in the emergency department. Pediatrics. 2014;133(4):635-642. doi:10.1542/peds. 2013-2600 [PubMed: 24616361]

79. Ponsford J, Willmott C, Rothwell A, et al. Impact of early intervention on outcome following mild head injury in adults. J Neurol Neurosurg Psychiatry. 2002;73(3):330-332. doi:10.1136/jnnp. 73.3.330 [PubMed: 12185174]

80. Centers for Disease Control and Prevention. HEADS UP. http://www.cdc.gov/headsup. Updated March 14, 2017 Accessed February 16, 2018.

81. Broglio SP, Cantu RC, Gioia GA, et al.; National Athletic Trainers' Association. National Athletic Trainers' Association position statement: management of sport concussion. J Athl Train. 2014;49(2):245-265. doi:10.4085/1062-6050-49.1.07 [PubMed: 24601910]

82. Adams RJ. Improving health outcomes with better patient understanding and education. Risk Manag Healthc Policy. 2010;3:61-72. doi:10.2147/RMHP.S7500 [PubMed: 22312219]

83. Castile L, Collins CL, McIlvain NM, Comstock RD. The epidemiology of new versus recurrent sports concussions among high school athletes, 2005-2010. Br J Sports Med. 2012;46(8): 603610. doi:10.1136/bjsports-2011-090115 [PubMed: 22144000]

84. Chrisman SP, Rivara FP, Schiff MA, Zhou C, Comstock RD. Risk factors for concussive symptoms 1 week or longer in high school athletes. Brain Inj. 2013;27(1):1-9. doi: 10.3109/02699052.2012.722251 [PubMed: 23252433]

85. Fay TB, Yeates KO, Taylor HG, et al. Cognitive reserve as a moderator of postconcussive symptoms in children with complicated and uncomplicated mild traumatic brain injury. J Int Neuropsychol Soc. 2010;16(1):94-105. doi:10.1017/S1355617709991007 [PubMed: 19835663]

86. Massagli TL, Fann JR, Burington BE, Jaffe KM, Katon WJ, Thompson RS. Psychiatric illness after mild traumatic brain injury in children. Arch Phys Med Rehabil. 2004;85(9):1428-1434. doi: 10.1016/j.apmr.2003.12.036 [PubMed: 15375812]

87. Ponsford J, Willmott C, Rothwell A, et al. Cognitive and behavioral outcome following mild traumatic head injury in children. J Head Trauma Rehabil. 1999;14(4):360-372. doi: 10.1097/00001199-199908000-00005 [PubMed: 10407209]

88. Olsson KA, Lloyd OT, Lebrocque RM, McKinlay L, Anderson VA, Kenardy JA. Predictors of child post-concussion symptoms at 6 and 18 months following mild traumatic brain injury. Brain Inj. 2013;27(2):145-157. doi:10.3109/02699052.2012.729286 [PubMed: 23384213]

89. Max JE, Pardo D, Hanten G, et al. Psychiatric disorders in children and adolescents six-to-twelve months after mild traumatic brain injury. J Neuropsychiatry Clin Neurosci. 2013;25(4):272-282. doi:10.1176/appi.neuropsych.12040078 [PubMed: 24247854]

90. Blume HK, Vavilala MS, Jaffe KM, et al. Headache after pediatric traumatic brain injury: a cohort study. Pediatrics. 2012;129(1):e31-e39. doi:10.1542/peds.2011-1742 [PubMed: 22144708]

91. Zonfrillo MR, Durbin DR, Koepsell TD, et al. Prevalence of and risk factors for poor functioning after isolated mild traumatic brain injury in children. J Neurotrauma. 2014;31(8):722-727. doi: 10.1089/neu.2013.3088 [PubMed: 24294826] 
92. Rivara FP, Koepsell TD, Wang J, et al. Disability 3, 12, and 24 months after traumatic brain injury among children and adolescents. Pediatrics. 2011; 128(5):e1129-e1138. doi:10.1542/peds. 2011-0840 [PubMed: 22025592]

93. Taylor HG, Orchinik LJ, Minich N, et al. Symptoms of persistent behavior problems in children with mild traumatic brain injury. J Head Trauma Rehabil. 2015;30(5):302-310. doi:10.1097/HTR. 0000000000000106 [PubMed: 25629259]

94. Levin HS, Hanten G, Roberson G, et al. Prediction of cognitive sequelae based on abnormal computed tomography findings in children following mild traumatic brain injury. J Neurosurg Pediatr. 2008;1(6):461-470. doi:10.3171/PED/2008/1/6/461 [PubMed: 18518697]

95. Smyth K, Sandhu SS, Crawford S, Dewey D, Parboosingh J, Barlow KM. The role of serotonin receptor alleles and environmental stressors in the development of post-concussive symptoms after pediatric mild traumatic brain injury. Dev Med Child Neurol. 2014;56(1):73-77. doi:10.1111/ dmcn.12263 [PubMed: 23992222]

96. Zemek R, Barrowman N, Freedman SB, et al.; Pediatric Emergency Research Canada (PERC) Concussion Team. Clinical risk score for persistent post-concussion symptoms among children with acute concussion in the ED. JAMA. 2016;315(10): 1014-1025. doi:10.1001/jama.2016.1203 [PubMed: 26954410]

97. Broglio SP, Puetz TW. The effect of sport concussion on neurocognitive function, self-report symptoms and postural control: a meta-analysis. Sports Med. 2008;38(1):53-67. doi: 10.2165/00007256-200838010-00005 [PubMed: 18081367]

98. Davis GA, Iverson GL, Guskiewicz KM, Ptito A, Johnston KM. Contributions of neuroimaging, balance testing, electrophysiology and blood markers to the assessment of sport-related concussion. Br J Sports Med. 2009;43(suppl 1):i36-i45. doi:10.1136/bjsm.2009.058123 [PubMed: 19433424]

99. Ellemberg D, Henry LC, Macciocchi SN, Guskiewicz KM, Broglio SP. Advances in sport concussion assessment: from behavioral to brain imaging measures. J Neurotrauma. 2009;26(12): 2365-2382. doi:10.1089/neu.2009.0906 [PubMed: 19715396]

100. Brooks BL, Daya H, Khan S, Carlson HL, Mikrogianakis A, Barlow KM. Cognition in the emergency department as a predictor of recovery after pediatric mild traumatic brain injury. J Int Neuropsychol Soc. 2016;22(4):379-387. doi:10.1017/S1355617715001368 [PubMed: 26786357]

101. Guskiewicz KM. Postural stability assessment following concussion: one piece of the puzzle. Clin J Sport Med. 2001;11(3):182-189. doi:10.1097/00042752-200107000-00009 [PubMed: 11495323]

102. Mittenberg W, Canyock EM, Condit D, Patton C. Treatment of post-concussion syndrome following mild head injury. J Clin Exp Neuropsychol. 2001;23(6):829-836. doi:10.1076/jcen. 23.6.829.1022 [PubMed: 11910547]

103. McCrory P, Meeuwisse WH, Aubry M, et al. Consensus statement on concussion in sport: the 4th International Conference on Concussion in Sport held in Zurich, November 2012. Br J Sports Med. 2013;47(5):250-258. doi:10.1136/bjsports-2013-092313 [PubMed: 23479479]

104. Halstead ME, Walter KD; Council on Sports Medicine and Fitness. American Academy of Pediatrics: clinical report: sport-related concussion in children and adolescents. Pediatrics. 2010;126 (3):597-615. doi:10.1542/peds.2010-2005 [PubMed: 20805152]

105. Silverberg ND, Iverson GL. Is rest after concussion "the best medicine?" recommendations for activity resumption following concussion in athletes, civilians, and military service members. J Head Trauma Rehabil. 2013;28(4):250-259. doi:10.1097/HTR.0b013e31825ad658 [PubMed: 22688215]

106. Moser RS, Schatz P, Glenn M, Kollias KE, Iverson GL. Examining prescribed rest as treatment for adolescents who are slow to recover from concussion. Brain Inj. 2015;29(1):58-63. doi: 10.3109/02699052.2014.964771 [PubMed: 25279423]

107. Moser RS, Glatts C, Schatz P. Efficacy of immediate and delayed cognitive and physical rest for treatment of sports-related concussion. J Pediatr. 2012;161(5):922-926. doi:10.1016/j.jpeds. 2012.04.012 [PubMed: 22622050] 
108. Brown NJ, Mannix RC, O’Brien MJ, Gostine D, Collins MW, Meehan WP III. Effect of cognitive activity level on duration of post-concussion symptoms. Pediatrics. 2014;133(2):e299-e304. doi: 10.1542/peds.2013-2125 [PubMed: 24394679]

109. Prins ML, Alexander D, Giza CC, Hovda DA. Repeated mild traumatic brain injury: mechanisms of cerebral vulnerability. J Neurotrauma. 2013;30 (1):30-38. doi:10.1089/neu.2012.2399 [PubMed: 23025820]

110. Giza CC, Griesbach GS, Hovda DA. Experience-dependent behavioral plasticity is disturbed following traumatic injury to the immature brain. Behav Brain Res. 2005;157(1):11-22. doi: 10.1016/j.bbr.2004.06.003 [PubMed: 15617766]

111. Terwilliger VK, Pratson L, Vaughan CG, Gioia GA. Additional post-concussion impact exposure may affect recovery in adolescent athletes. J Neurotrauma. 2016;33(8):761-765. doi:10.1089/ neu.2015.4082 [PubMed: 26421452]

112. Weinstein E, Turner M, Kuzma BB, Feuer H. Second impact syndrome in football: new imaging and insights into a rare and devastating condition. J Neurosurg Pediatr. 2013;11(3):331-334. doi: 10.3171/2012.11.PEDS12343 [PubMed: 23277914]

113. Bay E, Hagerty BM, Williams RA, Kirsch N, Gillespie B. Chronic stress, sense of belonging, and depression among survivors of traumatic brain injury. J Nurs Scholarsh. 2002;34(3):221-226. doi:10.1111/j.1547-5069.2002.00221.x [PubMed: 12237983]

114. Leddy JJ, Kozlowski K, Donnelly JP, Pendergast DR, Epstein LH, Willer B. A preliminary study of subsymptom threshold exercise training for refractory post-concussion syndrome. Clin J Sport Med. 2010;20(1):21-27. doi:10.1097/JSM.0b013e3181c6c22c [PubMed: 20051730]

115. Gagnon I, Galli C, Friedman D, Grilli L, Iverson GL. Active rehabilitation for children who are slow to recover following sport-related concussion. Brain Inj. 2009;23(12):956-964. doi: 10.3109/02699050903373477 [PubMed: 19831492]

116. Gagnon I, Grilli L, Friedman D, Iverson GL. A pilot study of active rehabilitation for adolescents who are slow to recover from sport-related concussion. Scand J Med Sci Sports. 2016;26(3): 299-306. doi:10.1111/sms.12441 [PubMed: 25735821]

117. Warburton DE, Nicol CW, Bredin SS. Health benefits of physical activity: the evidence. CMAJ. 2006;174(6):801-809. doi:10.1503/cmaj.051351 [PubMed: 16534088]

118. Thomas DG, Apps JN, Hoffmann RG, McCrea M, Hammeke T. Benefits of strict rest after acute concussion: a randomized controlled trial. Pediatrics. 2015;135(2):213-223. doi:10.1542/peds. 2014-0966 [PubMed: 25560444]

119. Penninx BW, Kriegsman DM, van Eijk JTM, Boeke AJ, Deeg DJH. Differential effect of social support on the course of chronic disease: a criteria-based literature study. Fam Syst Health. 1996;14(2):223-244. doi:10.1037/h0089816

120. Stålnacke BM. Community integration, social support and life satisfaction in relation to symptoms 3 years after mild traumatic brain injury. Brain Inj. 2007;21(9):933-942. doi: 10.1080/02699050701553189 [PubMed: 17729046]

121. McCauley SR, Boake C, Levin HS, Contant CF, Song JX. Postconcussional disorder following mild to moderate traumatic brain injury: anxiety, depression, and social support as risk factors and comorbidities. J Clin Exp Neuropsychol. 2001;23(6): 792-808. doi:10.1076/jcen. 23.6.792.1016 [PubMed: 11910545]

122. Gioia GA. Medical-school partnership in guiding return to school following mild traumatic brain injury in youth. J Child Neurol. 2016;31(1):93-108. doi:10.1177/0883073814555604 [PubMed: 25535055]

123. Gioia GA, Glang AE, Hooper SR, Brown BE. Building statewide infrastructure for the academic support of students with mild traumatic brain injury. J Head Trauma Rehabil. 2016;31(6):397406. doi:10.1097/HTR.0000000000000205 [PubMed: 26709582]

124. Ransom DM, Vaughan CG, Pratson L, Sady MD, McGill CA, Gioia GA. Academic effects of concussion in children and adolescents. Pediatrics. 2015;135(6):1043-1050. doi:10.1542/peds. 2014-3434 [PubMed: 25963014]

125. Babikian T, McArthur D, Asarnow RF. Predictors of 1-month and 1-year neurocognitive functioning from the UCLA longitudinal mild, uncomplicated, pediatric traumatic brain injury 
study. J Int Neuropsychol Soc. 2013;19(2):145-154. doi:10.1017/S135561771200104X [PubMed: 23157821]

126. Sady MD, Vaughan CG, Gioia GA. School and the concussed youth: recommendations for concussion education and management. Phys Med Rehabil Clin N Am. 2011;22(4):701-719, ix ix. doi: 10.1016/j.pmr.2011.08.008 [PubMed: 22050944]

127. Broglio SP, Collins MW, Williams RM, Mucha A, Kontos AP. Current and emerging rehabilitation for concussion: a review of the evidence. Clin Sports Med. 2015;34(2):213-231. doi:10.1016/j.csm.2014.12.005 [PubMed: 25818710]

128. DeMatteo C, Stazyk K, Giglia L, et al. A balanced protocol for return to school for children and youth following concussive injury. Clin Pediatr (Phila). 2015;54(8):783-792. doi: 10.1177/0009922814567305 [PubMed: 25601958]

129. US Department of Education website. Protecting students with disabilities. http://www2.ed.gov/ about/offices/list/ocr/504faq.html. Updated October 16, 2015 Accessed February 16, 2018.

130. Yeates KO, Luria J, Bartkowski H, Rusin J, Martin L, Bigler ED. Postconcussive symptoms in children with mild closed head injuries. J Head Trauma Rehabil. 1999;14(4):337-350. doi: 10.1097/00001199-199908000-00003 [PubMed: 10407207]

131. Gelfand AA, Goadsby PJ. Treatment of pediatric migraine in the emergency room. Pediatr Neurol. 2012;47(4):233-241. doi:10.1016/j.pediatrneurol.2012.06.001 [PubMed: 22964436]

132. Silberstein SD. Practice parameter: evidence-based guidelines for migraine headache (an evidence-based review): report of the Quality Standards Subcommittee of the American Academy of Neurology. Neurology. 2000;55(6):754-762. doi:10.1212/WNL.55.6.754 [PubMed: 10993991]

133. Lumba-Brown A, Harley J, Lucio S, Vaida F, Hilfiker M. Hypertonic saline as a therapy for pediatric concussive pain: a randomized controlled trial of symptom treatment in the emergency department. Pediatr Emerg Care. 2014;30(3):139-145. doi:10.1097/PEC.0000000000000084 [PubMed: 24583571]

134. Mucha A, Collins MW, Elbin RJ, et al. A brief vestibular/ocular motor screening (VOMS) assessment to evaluate concussions: preliminary findings. Am J Sports Med. 2014;42(10):24792486. doi:10.1177/0363546514543775 [PubMed: 25106780]

135. Alsalaheen BA, Mucha A, Morris LO, et al. Vestibular rehabilitation for dizziness and balance disorders after concussion. J Neurol Phys Ther. 2010;34(2):87-93. doi:10.1097/NPT. 0b013e3181dde568 [PubMed: 20588094]

136. Alsalaheen BA, Whitney SL, Mucha A, Morris LO, Furman JM, Sparto PJ. Exercise prescription patterns in patients treated with vestibular rehabilitation after concussion. Physiother Res Int. 2013;18(2):100-108. doi:10.1002/pri.1532 [PubMed: 22786783]

137. Ellis MJ, Leddy JJ, Willer B. Physiological, vestibulo-ocular and cervicogenic post-concussion disorders: an evidence-based classification system with directions for treatment. Brain Inj. 2015;29(2): 238-248. doi:10.3109/02699052.2014.965207 [PubMed: 25314613]

138. Schneider KJ, Meeuwisse WH, Nettel-Aguirre A, et al. Cervicovestibular rehabilitation in sportrelated concussion: a randomised controlled trial. Br J Sports Med. 2014;48(17):1294-1298. doi: 10.1136/bjsports-2013-093267 [PubMed: 24855132]

139. Lavigne G, Khoury S, Chauny JM, Desautels A. Pain and sleep in post-concussion/mild traumatic brain injury. Pain. 2015;156(suppl 1):S75-S85. doi:10.1097/j.pain.0000000000000111 [PubMed: 25789439]

140. Stores G. Children's sleep disorders: modern approaches, developmental effects, and children at special risk. Dev Med Child Neurol. 1999;41(8):568-573. doi:10.1017/S001216229900119X [PubMed: 10479046]

141. Baumann CR, Werth E, Stocker R, Ludwig S, Bassetti CL. Sleep-wake disturbances 6 months after traumatic brain injury: a prospective study. Brain. 2007;130(pt 7):1873-1883. doi:10.1093/ brain/awm109 [PubMed: 17584779]

142. Venter R. Role of sleep in performance and recovery of athletes: a review article. S Afr J Res Sport Phys Educ Recreation. 2012;34(1):167-184.

143. Owens JA, Mindell JA. Pediatric insomnia. Pediatr Clin North Am. 2011;58(3):555-569. doi: 10.1016/j.pcl.2011.03.011 [PubMed: 21600342] 
144. Mollayeva T, Pratt B, Mollayeva S, Shapiro CM, Cassidy JD, Colantonio A. The relationship between insomnia and disability in workers with mild traumatic brain injury/concussion: insomnia and disability in chronic mild traumatic brain injury. Sleep Med. 2016;20:157-166. doi: 10.1016/j.sleep.2015.09.008 [PubMed: 26790723]

145. Kemp S, Biswas R, Neumann V, Coughlan A. The value of melatonin for sleep disorders occurring post-head injury: a pilot RCT. Brain Inj. 2004;18(9): 911-919. doi: 10.1080/02699050410001671892 [PubMed: 15223743]

146. Broglio SP, Macciocchi SN, Ferrara MS. Neurocognitive performance of concussed athletes when symptom free. J Athl Train.2007;42(4):504-508. [PubMed: 18174938]

147. Broshek DK, Kaushik T, Freeman JR, Erlanger D, Webbe F, Barth JT. Sex differences in outcome following sports-related concussion. J Neurosurg. 2005;102(5):856-863. doi:10.3171/jns. 2005.102.5.0856 [PubMed: 15926710]

148. Braun M, Tupper D, Kaufmann P, et al. Neuropsychological assessment: a valuable tool in the diagnosis and management of neurological, neurodevelopmental, medical, and psychiatric disorders. Cogn Behav Neurol. 2011;24(3):107-114. doi:10.1097/WNN.0b013e3182351289 [PubMed: 21945982]

149. Moulding NT, Silagy CA, Weller DP. A framework for effective management of change in clinical practice: dissemination and implementation of clinical practice guidelines. Qual Health Care. 1999;8(3):177-183. doi:10.1136/qshc.8.3.177 [PubMed: 10847875]

150. Francke AL, Smit MC, de Veer AJE, Mistiaen P. Factors influencing the implementation of clinical guidelines for health care professionals: a systematic meta-review. BMC Med Inform Decis Mak. 2008;8(38):38. doi:10.1186/1472-6947-8-38 [PubMed: 18789150]

151. Titler MG. The evidence for evidence-based practice implementation In: Hughes R, ed. Patient Safety and Quality: An Evidence-Based Handbook for Nurses. Rockville, MD: Agency for Healthcare Research and Quality; 2008:1-49.

152. Arbogast KB, McGinley AD, Master CL, Grady MF, Robinson RL, Zonfrillo MR. Cognitive rest and school-based recommendations following pediatric concussion: the need for primary care support tools. Clin Pediatr (Phila). 2013;52(5):397-402. doi:10.1177/0009922813478160 [PubMed: 23447397]

153. National Center for Injury Prevention and Control. CDC Injury Center Research Priorities. Atlanta, GA: Centers for Disease Control and Prevention, US Dept of Health and Human Services; 2015 https://www.cdc.gov/injury/researchpriorities/index.html. Accessed February 16, 2018. 
Box.

\section{Assigning Level of Confidence in the Inference and Strength of Recommendation}

\section{Level of Confidence in the Inference}

- As part of the systematic review, the American Academy of Neurology Classification of Evidence Scheme ${ }^{17}$ was used to assign the risk of bias and assign a class for each study, including class I (eg, high-quality RCTs), class II (eg, RCTs with significant limitations), class III (eg, other controlled studies), and class IV (eg, no measures of the effectiveness or statistical precision).

- Workgroup members were presented with a series of potential recommendations and a rationale for each recommendation. The rationale was based on the research identified in the systematic review, as well as related evidence that pertained to the recommendation.

- Level of confidence in the inference was based on workgroup members' assessment of the cogency of the rationale supporting each recommendation and was assigned on the basis of the following 5 domains rated by workgroup members: rationale is logical, evidence statements are accurate, axioms are true, related evidence is strong and applicable, and internal inferences logically follow.

- Levels include high, moderate, low, or very low.

\section{Strength of Recommendation ${ }^{\mathrm{a}}$}

There is not a direct correspondence between the class of studies and confidence in the inference or strength of recommendation. While the class of studies is an important consideration, the methods that were used consider a number of additional factors in deriving these judgments. The determination by the workgroup of strength of recommendation was initially anchored to level of confidence in the inference but was modified on the basis of workgroup members' assessment of each recommendation, including the following: the importance of the outcome, benefit relative to harm, expected variation in patient preferences, financial burden relative to benefit expected, and the feasibility of the intervention (eg, the availability).

- Level A: The recommendation almost always should be followed.

- $\quad$ Level B: The recommendation usually should be followed.

- Level C: The recommendation may sometimes be followed.

- Level U: There is insufficient evidence to make a recommendation.

- $\quad$ Level R: The intervention generally should not be done outside of a research setting (applicable only to recommendations related to interventions).

Abbreviation: RCT, randomized clinical trial. 
${ }^{a}$ More detailed information related to how workgroup members assigned level of confidence in the inference and strength of recommendation can be found in the eAppendix in the Supplement. 


\section{Key Points}

\section{Question}

Based on current evidence, what are best practices for diagnosis, prognosis, and management/treatment of pediatric mild traumatic brain injury (mTBI)?

\section{Findings}

Based on a previous systematic review of the literature, this guideline includes 19 sets of recommendations on diagnosis, prognosis, and management/treatment of pediatric mTBI. Each recommendation was assigned a level of obligation (ie, must, should, or may) based on confidence in the evidence.

\section{Meaning}

Clinical guidance for health care professionals is critical to improving health and safety of this vulnerable population; the recommendations represent current best practices and comprise the first evidence-based clinical guideline to date for diagnosing and managing pediatric mTBI in the United States. 